\title{
An Investigation into Perception of Internal and External Business Environment by Small Medium Enterprise (SMES) - A case of Maramba Market in Livingstone, Zambia
}

\author{
Article by Jacob Manda \\ Texila American University Lusaka, Zambia Campus \\ E-mail: jacobmanda@yahoo.com
}

\begin{abstract}
This article is an extract of one of the objectives to the study that investigated the perceptions of small medium enterprises at marimba market in Livingstone district of Zambia. The study objectives were to establish the current status of small medium enterprises in the market and to determine the challenges of implementing their business ideas. Three leading entrepreneurs were interviewed to check their opinion and these deal in different products which are similar to other traders.

Data was collected using semi-structured questionnaires and an observation schedule. One questionnaire was used to collect data from the executive committee of the market and board members while another gathered data from the small-scale business owners. An observation schedule was used to collect data which seemed difficult to collect through semi-structured questionnaires. Qualitative data was analyzed and presented thematically, while quantitative data was analyzed through Social Package for Social Sciences (SPSS) and was presented in form of tables and figures.

The findings of the study were that small scale business enterprises held positive perceptions on the introduction of small capital investment for small medium enterprises in the market places such as marimba. However, most well-established business men and women held a negative attitude towards small medium enterprises due to informal trading approach. Numerous challenges to the successful implementation of the business plan and ideas in various sectors of the business. They included: some new comers in the business sector who preferred other products which do not suit the demand of the given context and this has led to a huge challenge because both the internal and external environments have not been read well by the small business enterprises.

The study suggested the following coping strategies and measures; Continuing business Professional Development (CBPD) meetings, increased administration and financial support, provision of small medium enterprises with equipment and infrastructure, sensitization on the importance of small business enterprises in the economy and the enhancement of the human resources with the knowledge of understanding the current business trends globally so as to avoid certain shocks which might come out as result of failure to read the market well.
\end{abstract}

Keywords: Investigation, Perceptions, Internal and external, business environment and small medium enterprises.

\section{Introduction}

\section{Background to the Study}

The origin of small medium enterprises can be traced back to the origin of mankind and that the subject forms an element of life. Mwanakatwe (1965) ${ }^{[19]}$ alludes that small business enterprises were introduced after independence in a formal way in Zambia business sector during the colonial period. Studies conducted on the history of business reveals that small businesses and others has always been in existence though regarded with varying degrees of importance and mostly stressing practical business activities without formal approach.

Small medium enterprises have been facing a number of implementation challenges in Zambia. Since independence, the Ministry of commerce trade and industry has implemented certain policies in an effort to protect the small business from exploitation by big businesses. The introduction of physical education during this period was not seriously done because there was no public awareness 
administered at any level of marketing in the Zambian markets. With this and many other challenges, most markets managed to include the elements of small medium enterprises (Mutiti, 2011). ${ }^{[18] .}$

Despite these challenges, most small medium enterprises management never got concerned with what went on in markets regarding the implementation of business plans. In that case, very little importance was attached to the business sector as it was considered a time waster in the preparation of small businesses which were emerging. Small medium business owners would always complain about how low the sector was ranked on the in the chamber of commerce trade and industry. Well meaningful enterprising businesses would implement the business but they received negative support and comments from all the stake holders from both senior businesses and the community. The kind of business that went on in such cases was also haphazardly done since no proper routine was followed. In most cases, small scale businesses would be left on their own doing business without the guidance of their friends who are well established.

However, the Ministry of commerce trade and industry has realized that small business medium enterprises have a unique but not exclusive role to play in the economy, MCTI (1996) and up holds the importance that the sector plays in promoting economic activities among people. Learners' physical, mental, social, emotional and spiritual development. This role is in two-fold; to enhance the business creativity and wellbeing and to teach them a wide range of business skills. Small business enterprise prepares the business owners physically, socially, mentally, emotionally, intellectually and culturally so that they can effectively contribute to national development.

Mufalali (1974) ${ }^{[16]}$ states that the business environment both internal and external helps to develop a health mindset towards business. It also gives appropriate alternatives to individual business learning styles, interests and problems. It includes among other things all practices that foster good business promotion, character building and acceptable values and attitudes in society as one do business. Internal and external environment offers scope for experimentation skills due to pressure from both sides, dramatization practices, excitement and freedom. This scope digs up the hidden and undeveloped sources of inherent skills and ability in the business sector so as to make them aware and develop confidence in their usage. Chamber of commerce (1995) ${ }^{[5]}$ asserts that business environment helps to prepare a business for what lays ahead of them. (1998) ${ }^{[4]}$ maintains that business activities employed in both internal and external environment make customers healthier in making decision about the product to buy.

While business environment is acclaimed as having immense benefits for people as well as the economy, Kilimbai (1991) ${ }^{[11]}$ showed that, it is characterized more by neglect than by attention and that in some African business industry, the status remained questionable due to the fact that it was non-examinable. Musangeya et al, (2000) ${ }^{[17]}$ adds that in some areas it was rated lowly and still at its infant stage, people had negative attitudes towards it. Negative attitudes arose when business owners were unaware of the matter and responsibilities of implementing the subject.

Many societies as restricted rules to business, and that its importance was to satisfy the market and recreational drives of man (Shehu, 2001). ${ }^{[23]}$ In its quest to improve the quality of business in Zambian trading sectors, the Ministry of commerce trade and industry (MCTI) ought to revise the trade policy in order to address serious issues in the business environment so as to avoid business facing the pain.

\section{Statement of the problem}

For a long time in Zambia small medium enterprise have been sidelined as a sector due to the lack of national interest in the area (Mutiti, 2011) ${ }^{[18 .]}$ In 2013 the Government of the republic of Zambia through the Ministry of Commerce Trade and indusrty revised the business policy. The revision of the Zambian business by the Ministry saw an introduction of formal business connected to the issues on the ground. Since the introduction of small business enterprises in however, little or no research has been conducted to investigate the perceptions on the internal and external business environment by the small business enterprises. 


\section{Significance of the study}

The findings of this study may enable the policy makers in the Ministry of Commerce Trade and Industry (MCTI) to find remedies in addressing the perceived perceptions among the small medium enterprises. The outcome of this research, might also contribute to the business sector and the nation economy at large to appreciate and finally this study has contributed knowledge to the scholarly world.

\section{Study location}

The study was conducted in Livingstone District in the Southern Province of Zambia. Maramba market was selected to take part in the study. This was the only market that took part in this. The researcher knew that the selected market was in the position to provide him with necessary respondents since they all had an opportunity to choose this type of business to offer to their community.

\section{Literature review}

Internal and external business environment in relation with small medium enterprises is an absolutely fundamental and essential part of a balanced approach in the world over. It provides a contrast to the relative inactivity of the business setting and has both physical and economic benefits to socio-economical sector. No other single factor in the business environment provides the stimulation for mind and body to work together in harmony among business owners.

Price $(1980)^{[21]}$ reviewed that awareness, movement experiences are fundamental to any program As one of the least considered business prospects of the institutions (Casey and O'donavan, 2015). ${ }^{[3]}$ Business environment has repeatedly sought to be seen as a legitimate venture with equal standing to its traditionally more highly valued venture in business sector.

The existence of formal enterprise is expected to bring about a significant change in the landscape for business environment of small medium enterprises. Previous research conducted in England revealed that the introduction of equity partners in business and equal trade fair through improving ways of doing business.

In her research on business environment perceptions of externally prescribed in Scotland, MacPhail $(2007)^{[13]}$ found that many business owners felt that they and their departments were well positioned for a number of reasons. These included firstly, that they were motivated in at this level and believed that they would be successful in gaining high gains for their customers.

From these outcomes MacPhail (2007) ${ }^{[13]}$ reported that some "admitted that the more attractive feature of the introduction of examinable business as opposed to addressing customer needs was the rising of their own status." Interestingly the conviction that small business enterprises have sufficient expertise to contrasts with concerns about the business content knowledge of neophyte (Siedentop, 2002). ${ }^{[24]}$

In considering a landscape dominated by other foreign business owners, Siedentop (2002) ${ }^{[24]}$ argued that as a consequence of rapid reconceptualization as an important aspect, the practitioner was being increasingly stripped of the basic knowledge needed to practically operate in this sector. Siedentop (2002) ${ }^{[24]}$ concluded that while a return to the days of focusing on practical business skills was not the solution, small medium business owners did need to understand both theoretically and as performers. In other words they needed to greatly enhance their practical ways and knowledge.

In his thought on the future of small business enterprises and the business environment, Kirk $(2010)^{[12]}$ maintained that the dominant and change-resistant form of the internal and external environment stunted growth of business. Kirk (2010) ${ }^{[10]}$ also proposed, in keeping with the arguments of Siedentop (2002), ${ }^{[2]}$ that the examining business environment has led to a form of an approach that has seen a "reduction and marginalization of the experience of practical activity which in turn has produced business owners who are better suited to run small businesses.

The provision of national business policy is a new concept in Zambia and is expected to boost the implementation of business in Zambian. A general understanding of this concept is that, examining small business with good business environment will raise the importance and status of the matter. 
Dunn and Fait (1987) ${ }^{[6]}$ point out that business environment provides experiences that will enhance growth of the business. Business owners must therefore, be encouraged to teach new comers in the industry concepts and skills inherent in a wide selection of business. Ministry of Commerce Trade and Industry (1996) ${ }^{[15]}$ states that Zambia needs to improve ways of doing business by creating a conducive environment in the existing labor market. As almost all of the factors that determine effectiveness are in need of special attention. This shows that support for improved equipment in are needed in all.

Mwanakatwe (1965) ${ }^{[19]}$ business environment in Zambia was very common predominantly during traditional methods of doing business and that it included practical training designed to provide good upbringing of the individual member of a given group to live a useful and happy life in society. The description of by Mwanakatwe(1965) ${ }^{[19]}$ business environment with the focus on internal and external environment emphasizes that it was aimed at the development of the peoples emotional, social and intellectual capabilities of citizens. It is stated that the ways in which people use this ability is related to other aspects of their functioning as whole persons.

\section{Research methodology}

\section{Research design}

This study was designed in form of a case study. A case study was being adopted because it allowed for the collection of data in a particular business environment and gave a detailed description about a phenomenon. The study used both qualitative and quantitative techniques with the help of semi structured questionnaires for data collection. This approach helped to get many views from both written materials and those on the ground to enable the researcher come up with concrete conclusions and recommendations. Phenomenological approach was also be used to gain a deeper understanding of the experiences of individual businesses. This helped the researcher understand how participants experienced some phenomenon and how they described an extent of the situation since participants had lived the experience as opposed to third party experience.

\section{Target population}

The study targeted maramba market in Livingstone District of Southern Province; all small medium enterprises businesses were also taken on.

\section{Sample size}

The total sample size of this research was sixty (60) participants who comprised of three (3) Big business owners, thirty (30) small business owners, (27) twenty-seven consumers who form part of the community where the business take place.

\section{Sampling procedure}

The study used multistage sampling technique. The researcher used purposive sampling method to select the big business owners, small business owner and the category of consumers. Simple random sampling technique was used to select the small business owners from the market place.

\section{Instruments for data collection}

The researcher carefully prepared two different types of semi-structured questionnaires for members of big business, small business owners and consumers. The other questionnaire was specifically prepared to gather data from the general members of the community. In addition to that, the researcher prepared an observation schedule which he used for conducting observations in the market that took part in the research.

\section{Data analysis techniques}

Data collected was analyzed through Statistical Package for Social Sciences (SPSS) version 20 software and used excel to generate figures and tables. Qualitative data was analyzed following emerging themes and sub themes. 


\section{Findings and discussion}

Figure 3.1 below indicates respondents' view on whether investigation in the' perception on internal and external environment had a major role to play in the implementation of small business enterprises. The analysis indicates, thirty-two giving a percentage of $53 \%$ of the respondents who strongly agreed while twenty-four representing $40 \%$ agreed that small medium business perception on business environment played a major role in the implementation of business plan. On the other hand, four respondents representing $7 \%$ disagreed to the statement. The results meant that a majority $93 \%$ of the respondents supported the assertion that small medium business perception had a major role to play in the implementation of business.

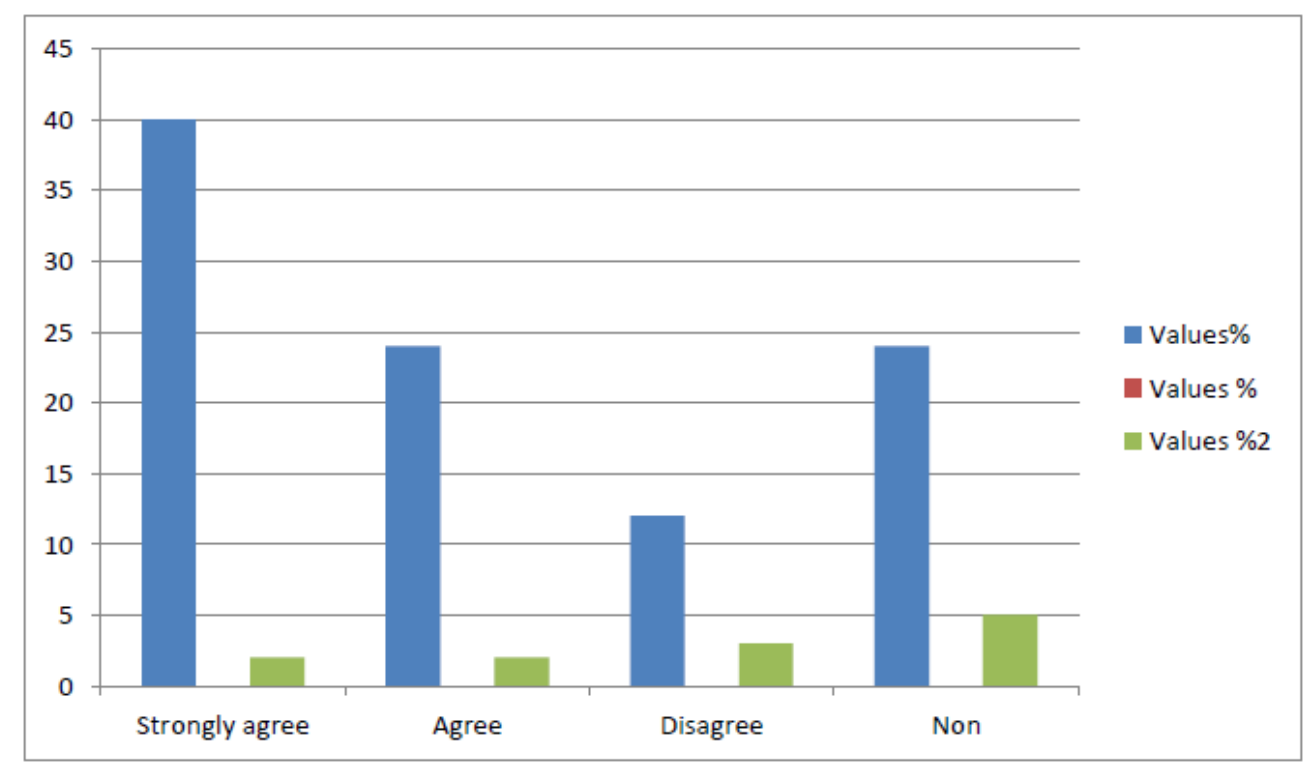

Figure 3.1. Small Medium Enterprises' Perception on internal and external business environment plays a major role in determining the Implementation of business

The study established that the current status of external and internal business environment is worrying. However, the analysis of the research results revealed that the introduction of small medium enterprises by the government through the Ministry of Commerce trade and industry (MCTI) in the market was expected to result in changing the negative attitudes held by administrators in the business sectors, some of the business owners, traders of other products, the community and manufacturers. Change of attitude by administrators was expected to result in more budgetary allocation to growing more entrepreneurs. More budgetary allocation to the sector meant empowering the people with more finances which would enable the sector to acquire enough products, improving and developing of wellbeing of the economy in order to facilitate growth domestic products.

The findings of the current research were consistent with the state of doing business in the United Kingdom (UK). Ways of doing business as small business in England is regarded as a valuable and a necessary element respected and adequately budgeted for (Green, 2005) ${ }^{[7]}$ In this regard Green, $(2005)^{[7]}$ found that small medium enterprise' perceptions of internal external environment had a great influence on the implementation of business in the market place. A positive perception and adequate support towards it was also expected to reduce the gap that exists between major and minor business owners and those of other tradition business since an improvement in the participation in economic activities by the business community would tremendously improve their performance in all aspects of business, the situation which would be appreciated by all the stakeholders in the Ministry of Commerce Trade and Industry.

The current study has established that the current status of internal and external business environment in market places is such that there exists a gap between major and minor business owners and those doing fine usually undermine the achievements of the small ones and this situation limits the growth of business sector. The current study was however consistent with Hardman $(2008){ }^{[8]}$ who noted negative attitudes amongst business owners and said small business enterprise was 
ISSN: $2520-310 \mathrm{X}$

regarded a lower status, peripheral way of doing business, as non-constructive and vocationally nonproductive, lacking in business value and merely as a compensatory economic activity.

In this regard, the current study emphasized the importance of according internal and external business environment small medium enterprise a status comparable to that of big or major businesses equal environment despite the situations. Such consideration is an important condition for the success of business introduced in market.

The study revealed that if administrators and small medium enterprises' perception of internal and external business environment could be changed toward helping newcomers on the market, in return the consumers would be more excited and see small businesses grow all altogether. The study also established that both internal and external business environment usually faced great difficulty in getting business operating permission from commerce trade and industry offices to allow them to take part in economic activities especially those performed within and outside the market. The study revealed that at the market under study, a skilled and talented business woman in business always hesitated to accompany the other big business owners because they looked at her as still young in the business and lacks the ideas. This scenario indicates that among business owners who are doing well currently hold negative perceptions towards internal and external business environment.

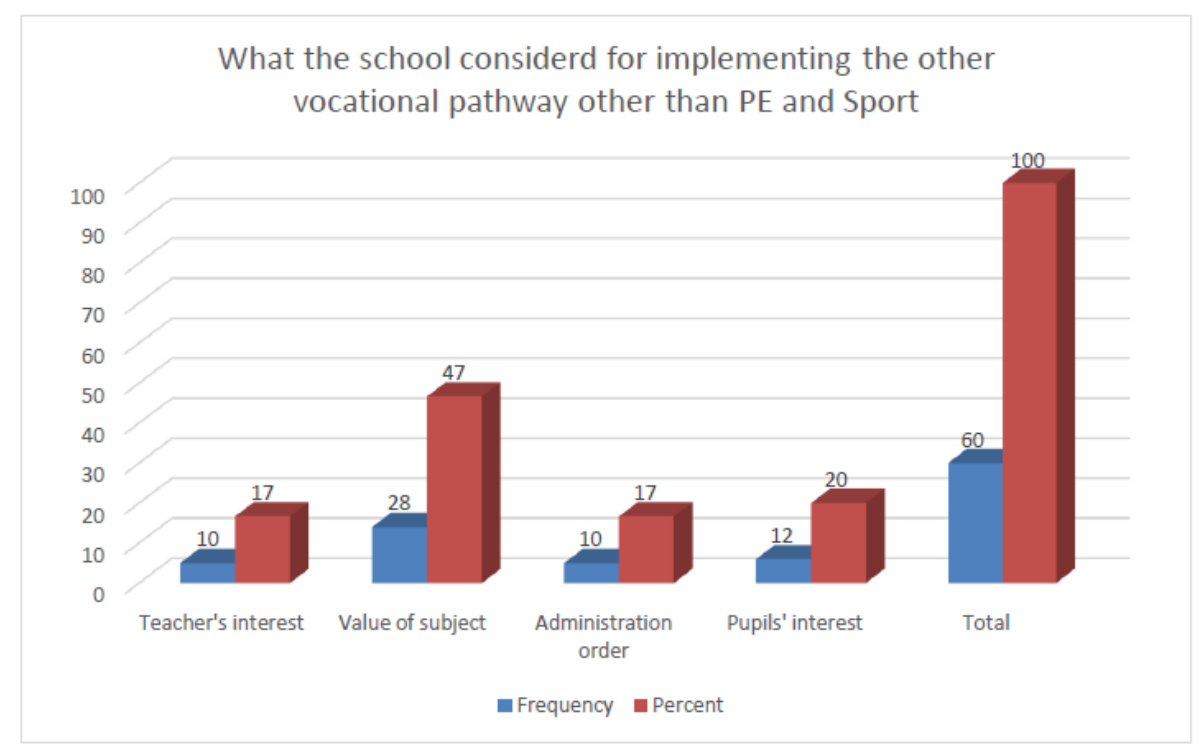

Figure 3.2. Business owners accounting for internal and external business environment

In response, as figure 3.2 above indicates, it was discovered that twenty two participants of sixty comprising of business administrators and major and minor business owners representing 37\% strongly agreed to the assertion that only a few small business enterprises implemented their business despite the external and internal shocks on the market, while thirty four representing 57\% agreed and only four out of sixty representing $6 \%$ of the respondents strongly disagreed to the assertion. This meant that a majority 47 respondents out sixty culminating into $94 \%$ were in support of the statement that most small medium enterprises adopted other business pathways and sort.

The current study realistically established that out of the total number of small business enterprises that took part in the survey, only one enterprise implemented her own business despite shocks on the market. Therefore, the current study established that negative attitude towards internal and external business environment mainly by the business administration and major business owners, who are responsible for choosing the direction to be implemented in market, were the major cause of dropping in the business. Respondents were again asked to state what they considered most for them to choose to implement both internal and external business environment as important factors for their business in the market. 


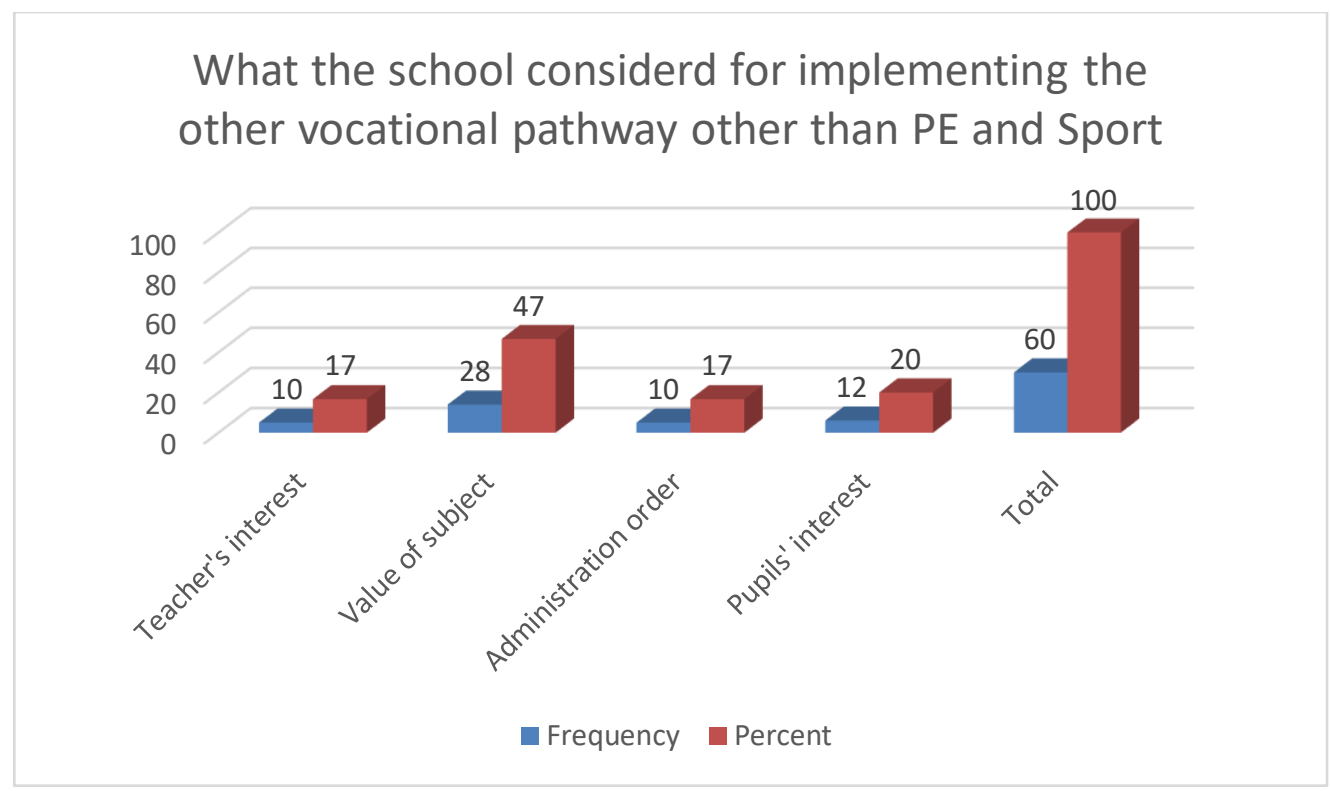

Figure 3.3. Reasons for implementing other vocational pathways

In response to this, ten of the sixty respondents culminating into $16 \%$ indicated that they considered teacher's interest in the subject for them to implement the vocational pathways in their schools, twenty eight out of sixty representing $46 \%$ of the respondents indicated that they considered the value of the subject under implementation, ten of the sixty respondents culminating into $17 \%$ indicated that it was an administrative order for them to implement a particular pathway while the remaining twelve giving a representation of $20 \%$ of the respondents responded that they followed pupils' interest. However, a majority of $46 \%$ of the respondents indicated that they considered the value of the subject for them to implement a particular pathway. The fact that physical education was less implemented in secondary schools as compared to other subjects meant that administrators, teachers including pupils considered physical education and sport to be of less value than other subjects.

The current study advanced other reasons for only a few schools having implemented Physical Education and Sport. They included the lack of adequate sports infrastructure and equipment in all the schools under study, inadequate trained teachers of Physical education and Sport and the negative perception by most teachers and administrators that it was expensive to implement Physical education and sport as compared to other subjects on the school curriculum. One of the schools felt that a hilly terrain at their schools would not support the implementation of physical education and sport and they automatically considered implementing other subjects in place of physical education and sport. It was however, surprising to note that some schools thought that physical education and sport was still unexaminable subject and indicated that the absence of examinations would make it difficult for most schools to implement Physical Education and Sport.

When asked to comment on whether the introduction of examinations in physical education and sport in secondary schools would raise the status of physical education, a majority of respondents thought that the presence of national examinations in secondary school physical education and sport would boost the status and value of the subject. It was sad however, to note that though the respondents felt that examinations in physical education and sport would boost the status of the subject, only one school out of the three successfully implemented the subject.

The inferiority of physical education as an academic subject is worrying. The current study revealed that pupils, administrators and teachers who took part in the study considered physical education and sport as an inferior subject as compared to other vocational pathways. When asked to comment on the perception that learners who took physical education and sport as a subject were looked down upon by pupils taking other subjects, twelve out of the sixty respondents who took part in the study culminating into $20 \%$ strongly agreed that pupils who took physical education and sport as a subject were indeed looked down upon by fellow students who took other subjects, thirty two 
respondents representing 53\% agreed, while sixteen respondents representing $27 \%$ of the total sixty respondents disagreed to the statement. From this analysis, the results indicate that a majority of $73 \%$ respondents supported the statement that pupils taking physical education and sport were looked down upon by pupils taking other subjects.

Figure 3.5. Physical Education and sport is considered inferior

One pupil was heard saying physical education was meant for the academically underperforming students to be kept in school. The perception that most pupils and people hold about physical education is that, it is not an intellectual subject hence, befitting those students with academic performance challenges. The study also established that parents and pupils had fears about pupils taking physical education and sport not easily accessing good jobs in future. This study established that people have a perception that, it would be very difficult for pupils taking physical education and sport to access good jobs after completing school. The current study was however not consistent with the study conducted by Green (2005) ${ }^{[7] .}$ In England which established that, pupils had a lot of employment opportunities in physical education presented to them in the post school environment.

Therefore, physical education and sport in our context and that of England are not the same and this calls for the authority to use appropriate measures of contextualising the subject in order to address issues taking place in our context.

Negative perception towards physical education and sport by most administrators, subject teachers and pupils was one of the areas that hampered the successful implementation of physical education and sport in most secondary schools.

Figure 3.4. Most teachers and pupils have a negative attitude towards physical education

After conducting an analysis, out of the sixty respondents ten representing $17 \%$ strongly agreed, that most teachers and pupils had a negative attitude towards physical education and sportwhile thirty culminating into $47 \%$ agreed to the assertion. However, twelve representing $20 \%$ of the respondents disagreed and another ten representing $17 \%$ of the sixty respondents strongly disagreed to the assertion that most teachers and pupils had a negative attitude towards physical education and sport. The study however, established that a majority of forty respondents culminating into $64 \%$ of the respondents perceived that most teachers and pupils had a negative attitude towards physical education and sport. The study revealed negative perceptions of most pupils and teachers towards examinations in secondary school physical education and sport possibly due to the low status of physical education in most secondary schools and the perceived lack of employment opportunities for physical education students after completing school. Most pupil respondents who indicated positive attitudes towards examinations in secondary school physical education seemed to be good at sport and thought this would be a way of continuing their education and getting qualified in something they deem to be their strengths.

However, pupil respondents who showed negative perceptions towards examinations in secondary school physical education tend to be the children that are highly academic and as a result tend to pursue more of a scientific area and those students who were not very good at physical education in the first place. Students' participation in physical education and sport has a lot of benefits, for instance; athletes enjoy the increase in physical fitness, introduction to a healthy lifestyle and also to a life-long sport or a career in sport. Despite the advantages outlined, respondents reported low levels of interest to participate in physical education and sport lessons as they thought the subject was not important in their lives. The current study has further revealed that, teachers trained in physical education did not actually teach the subject in their schools but taught other subjects instead. The reasons advanced for this situation were that administrators and physical education teachers had a negative perception towards physical education and that such schools never implemented physical education pathways hence teachers taught other subjects.

This attitude, resulted in pupils concentrating more on other school subjects which they perceived would contribute to their overall mark in the academic subjects. The situation suggests that examinations in secondary school physical education were very important in contributing to the overall raise of the status of physical education and sport in secondary schools which would in turn 
influence a greater level of participation in both physical education and extra curricula activities by both teachers and pupils.

\section{Conclusions and Recommendations}

In the light of the analysis and discussion of the teachers' perception towards examinations in secondary school physical education and sport, this research report has established that most teachers of physical education and sport emphasized the need for examinations in the subject which are expected to produce a positive change of attitude towards physical education and sport especially on teachers of other subjects, administrators especially those specialized in other subjects other than physical education and sport and parents as well as the society at large.

Teachers of physical education and sport felt that the introduction of examinations in secondary school physical education and sport would highly motivate students to participate in both physical education and sport as a subject and as sporting activities in secondary schools. The current study established that it is the perception held by administrators and teachers that affected the decision to either implement physical education and sport or implement other vocational pathways in their institutions. The study concluded that teachers' perception played a major role in determining the implementation of physical education and sport in secondary schools. The study established that only one secondary school out of the three secondary schools implemented physical education and sport as their vocational pathway subject while the rest decided to implement other subjects. The study has also revealed that administrators, teachers and pupils reported that learners who took physical education and sport in their classes were looked down upon by learners taking other subjects. Reasons given for such a perception were that, it was difficult for pupils taking physical education to find good jobs after finishing school and that the subject was considered an extracurricular activity and not an academic subject. To add on, this research has established that most physical education and sport trained teachers taught other subjects other than physical education and Sport in their schools. This scenario indicates that physical education and sport was less implemented in most secondary schools.

The study has however made the following recommendations: 1. The Ministry of General Education for instance, Senior Education Standards Officers Expressive Arts (SESO) should review and audit school facilities to ensure students have access to the necessary equipment to meet the requirements of examinations in secondary physical education. 2. The Ministry of General Education and teachers should conduct sensitization campaigns to help correct the perception that physical education and sport is a co-curricular and non-essential subject. 3. School administrations should fully support the Expressive Arts Departments by increasing funding to enable them buy and improve physical education and sport equipment and infrastructure to effectively implement examinations in physical education and sport in secondary schools. 4 . The government should deploy more teachers of physical education and sport to secondary schools. 5. Physical education teachers should be appraised and supervised by qualified physical education personnel since working under a Head of Department (HOD) specialized in other subjects other than physical education impacts negatively on prestige and professional development.

\section{References}

[1]. Alexander, K., 1987. What method of business should have told you? ACHPER National Journal, 117, pp.23-26.

[2]. Brown, T. and Penney, D., 2013. Learning 'in', 'through 'and 'about 'business movement? European Prime business Education Review, 19(1), pp.39-61.

[3]. Casey, A. and O'Donovan, T., 2015. Small business: adhering to principles of the business sector 20(4), pp.347-365.

[4]. Chan, K. L 1998. Business environment. Windsor: Human kinetics.

[5]. Department for Business. 1995.. London: HMSO.

[6]. Dunn, J.M and Fait, H.F. (1989) Special approach to business. New York: WM C. Brown Publishers.

[7]. Green, K. 2005. Examination of the business: a 'new orthodoxy' in business. essential issues, ed. K. Green and K. Hardman, 143-160. London, Sage.

[8]. Hardman, K. 2008. Business environment in communities: A global perspective. Kinesiology, 40(1): 5-28. 
DOI: 10.21522/TIJMG.2015.SE.19.01.Art023

ISSN: $2520-310 \mathrm{X}$

[9]. Kakuwa, M. 2004. Zambia Traditional business and Activities. Lusaka: Kopinor. 